\title{
MWCNT/Fibrin Bionanocomposites by in situ Enzymatic Polymerization
}

\author{
Mijin Kim, Jun Ho Jang, Jung Hun Han, Yong-Won Lee, ${ }^{\dagger}$ Sang-min Cho, ${ }^{\dagger}$ Sung-Yong Son, ${ }^{\ddagger}$ John Hulme, \\ Insung S. Choi, ${ }^{\dagger, *}$ Hyun-jong Paik, and Seong Soo A. An ${ }^{\text {s.* }}$ \\ Department of Polymer Science and Engineering, Pusan Kational Lniversity, Busan 609-735, Korea \\ ${ }^{*}$ E-mail: hpaikiapusan.ackr \\ ${ }^{\dagger}$ Department of Chemistry, KAIST, Daejeon 305-701. Korea. E-mail: ischoiokaistac.kr \\ ${ }^{\ddagger}$ College of Information Technologv. Kinngwon University, Gyeonggi $+61-701$, Korea \\ SGachon BioNano Research Institute, Kvingwon University, Gyeonggi +61-701. Korea \\ ${ }^{*}$ E-mail: seongaan akvingwon.ack $k$ \\ Received November 11, 2008, Accepted December 29, 2008
}

\begin{abstract}
In this work multiwalled carbon nanotube (MWCNT)/fibrin hybrid structures were synthesized via the transglutaminase-catalyzed polymerization of fibrinogen (FBG). Specifically, FBG was tethered onto oxidized MWCNTs by amide coupling, and the in situ polymerization of FBG to fibrin was performed by plasma transglutaminase (Factor XIIIa) in the presence of thrombin. The attached FBG was found to be biologically active and was polymerized to fibrin by thrombin and Factor XIIIa. MWCNT-FBG and MWCNT-Fibrin structures were characterized by FT-IR spectroscopy, transmission electron microscopy, and energy-dispersive X-ray (EDX) spectroscops
\end{abstract}

Key Words: Bionanocomposites, Multiwalled carbon nanotube, Transglutaninase-catalyzed polymerization, Fibrinogen. Fibrin

\section{Introduction}

Carbon nanotubes (CNTs) possess many interesting and unique properties. They are found in every'day applications. such as field emission displays. energy storage devices, nanoelectronics and scaffolds for tissue engineering. ${ }^{1-5}$ Recently. the unique properties of CNTs have been utilized in biological and biomedical devices. They have been employed in a variety of dnig and gene delivery systems. and anticancer treatments. ${ }^{6-8}$ Various methods for functionalizing CNTs with organic and inorganic materials or biomolecules. such as peptides. DNA and proteins have been recently reported ${ }^{9.12}$

In this stidy. fibrinogen (FBG) was selected as a potential protein for conjugation to CNTs. As an acute phase defensive plasma glycoprotein FBG acts as a core entity in the final phase of blood coagulation. ${ }^{13.14}$ The main function of FBG is the polymerization of a three-dimensional network of fibrin fibers ${ }^{13.14}$ FBG plays a role in cancer and tumor growth. ${ }^{15-18}$ cell migration ${ }^{19.27}$ cellular differentiation ${ }^{3-1-33}$ and platelet regulation. ${ }^{2+, 55}$ In addition FBG fragments (D-Dimer) act as markers for various cardiovascular diseases. ${ }^{26}$ Even though high concentrations of FBG exist in blood $(\sim 3 \mathrm{mg} / \mathrm{mL})$, FBG monomers are inert. poly merized by the thrombin and others co-factors involved in the regulation of the transglutaminase pathway. 28.29

In this paper the free amine groups of FBG and the carboxylic acid groups on the ends and sidewalls of oxidized multiwalled carbon nanotubes (MWCNTs) were crosslinked to each other via an EDC based coupling reaction. The functionalized bio-nanotubes were polymerized using the for-mentioned pathway forming a novel bio-composite material. the properties of which have been highlighted and discussed within.

\section{Experimental Section}

Materials. Multiwalled carbon nanotubes (MWCNTs, $10-25 \mathrm{~nm}$ in diameter. $10-50 \mathrm{~m}$ in length. produced by the CVD process) were purchased from Iljin Nanotech. and were used as received. Fibrinogen ( $\mathrm{F}$ 3879) and thrombin ( $\mathrm{T}$ 4393) were purchased from Sigma Inc. Plasma transglutaminase (FXIII. HCXIII-0160) was purchased from Haentech. Inc. Imject Immunogen EDC Conjugation Kits was purchased from Pierce Biotech, Inc. Fibrin polymerization inhibitor, H-Gly-Pro-Arg-Pro-NH2. (GPRP. H-1998) was purchased from Bachem. Inc.

Characterization. Transmission electron microscopy (TEM) images were recorded with a Hitachi $\mathrm{H}-7600$ microscope at $100 \mathrm{kV}$. Energy dispersion of X-ray spectroscopy (EDX) coupled with TEM was performed with a JEM-2010 electron microscope JEOL HIGHTECH at $120 \mathrm{kV}$. Infrared (IR) spectra were obtained with a JASCO FT-IR 460 PLUS.

Oxidation and shortening of MWCNTs. The chemical oxidation and shortening of MWCNTs were carried out in a misture of concentrated $\mathrm{H}_{2} \mathrm{SO}_{4}$ and $\mathrm{HNO}_{3}$ (3:1) under sonication (Bransonic, model 1510R-PTH. $42 \mathrm{kHz}$ ) for $24 \mathrm{~h}$ at temperatures between $35^{\circ} \mathrm{C}$ and $40{ }^{\circ} \mathrm{C}$. The remaining mixture was diluted with $2 \mathrm{~L}$ of water, and MWCNTs were collected after the centrifugation under $2500 \mathrm{rpm}$ for $30 \mathrm{~min}$. The resulting MWCNTs were further polished in a mixture of concentrated $\mathrm{H}_{2} \mathrm{SO}_{4}$ and $30 \%$ aqueous $\mathrm{H}_{2} \mathrm{O}_{2}(4: 1)$ with sonication (Bransonic, model 1510R-PTH. $42 \mathrm{kHz}$ ) for $24 \mathrm{~h}$ at temperatures between $35^{\circ} \mathrm{C}$ and $40^{\circ} \mathrm{C}$. After the sonication. the functionalized MWCNTs were washed 3 times in water then 2 times in acetone and in hexane respectively.

Conjugating fibrinogen (FBG) to MWCNT-COOH and 
polymerization of MWCNT-FBG. Conjugation of FBG to MWCNT-COOH was carried out by following the manufacturer's instructions. The amine group of Lys in FBG was coupled with the carboxyl acid group on MWCNT-COOH by l-ethyl-3-[3-dimethỵlaminopropyl] carbodiimide hỵddrochloride (EDC)-mediated reaction Briefly, $5 \mathrm{mg}$ of MWCNT-COOHs were suspended in $2 \mathrm{~mL}$ of the EDC conjugation buffer ( 10 $\mathrm{mM}$ potassium phosphate and $0.15 \mathrm{M} \mathrm{NaCl}$. pH 5.5). EDC ( $10 \mathrm{mg}$ ) was dissolved in $1 \mathrm{~mL}$ of deionised water $\left(\mathrm{dH}_{2} \mathrm{O}\right)$. and $100 \mu \mathrm{L}$ of the EDC solution was added to the MWCNT-COOH suspension. Then $4 \mathrm{mLs}$ of FBG monomer solution (2.5 $\left.\mathrm{mg} / \mathrm{mL}, \mathrm{dH}_{2} \mathrm{O}\right)$ containing $0.5 \mathrm{~mL}$ of $\mathrm{GPRP}(200 \mu \mathrm{g} / \mathrm{mL})$ was prepared. The excess GPRP was removed by dialysis. and concentrated to $2.5 \mathrm{mg} / \mathrm{mL}$ using a concentrator (Amicon USA). The resulting FBG $(2 \mathrm{~mL})$ solution was added to the MWCNT. $\mathrm{COOH}$ suspension; the mixture was then gently vortexed in an incubator for $2 \mathrm{~h}$ at room temperature. MWCNT-FBG was desalted in PBS buffer then concentrated, with a molecular cut-off of $100.000 \mathrm{Da}$ for $10-15 \mathrm{~min}$ at $1500 \mathrm{rpm}$.

The polymerization of MWCNT-FBG to MWCNT-fibrin was carried out by the addition of thrombin $(\mathrm{l} \mu \mathrm{g})$ and plasma transglutaminase $(2 \mu \mathrm{g})$ in PBS with $\mathrm{CaCl}_{2}(50 \mathrm{mM})$ at $37^{\circ} \mathrm{C}$ for $15 \mathrm{~min}$. The resulting MWCNT-fibrin was washed with PBS.

\section{Results and Discussion}

The amide bond between fibrinogen and MWCNT-COOH was formed using an EDC-based coupling reaction. which cross-linked the carboxyl and amine groups. EDC reacted with a carboxyl group on MWCNTs. forming an amine reactive intermediate. This intermediate may react with an amine group of Ly's in FBG. yielding a conjugate of the two entities. joined by a stable amide covalent bond. Fibrin polymerization inhibitor, GPRP. was added to the FBG solution. GPRP could bind into the polymerization pocket of the activated fibrin, preventing any unwanted poly merization reaction during the conjugation of fibrinogen onto MWCNTs. and keeping FBG as monomer. Activated Factor XIII (Factor XIIIa) stabilized the blood clot by cross-linking fibrin monomers between Lys and Gln residues. especially in a-and g-chains of fibrin, in the final stages of the coagulation cascade. As only non-proteolytic enzyme of the coagulation cascade. Factor XIII belonged to a family of transglutaminase. In plasma. Factor XIII existed as a tetramer $(\mathrm{Mw}=$
320.000 ), where two pairs of subdonain (A2B2) are held together by noncovalent bonds. ${ }^{38}$ Thrombin activates the zymogen Factor XIII to the active form Factor XIIla by removing $4000 \mathrm{MW}$ fragment from the $\mathrm{NH}_{z}$-terminals of both A chains. The full activity of Factor XIIIa can be gained by addition of $\mathrm{CaCl}_{2}$. where the catalytic activity is located in the A subunits. The A subunit contains 6 free sulflydryl groups one of which was the active site. ${ }^{29}$ Among the transglutaminase family. only plasma Factor XIII exists as zymogen in wo. Factor XIIIa increases the stability: insolubility. elasticity and its resistance against lysis of the clot. ${ }^{3 t}$

Figure 1 shows the TEM images of MWCNT-COOH (a). MWCNT-FBG (b), and MWCNT-Fibrin (c). The specimens for TEM measurements were prepared by depositing an aqueous drop of dipersed MWCNT-COOH, MWCNT-FBG, and MWCNT-Fibrin onto carbon-coated copper grids. Figure I(b) revealed that the layer of FBG was formed on the surface of MWCNTs. Figure l(c) indicated that cross-linking of MWCNT-FBG occurred after the enzymatic polymerization.

EDX coupled with TEM, measuring the atonic composition. was used to analyze the elements of the dark spots shown in Figure I(c). Figure 2 shows the TEM-EDX analy'sis of MWCNT-FBG (a) and MWCNT-Fibrin (b). The relative intensity of calcium was increased after the polymerization. This result indicated that the element of the dark spots might be calcium. which was used in the polymerization of MWCNT-Fibrin.

Figure 3 shows the IR spectra of MWCNT-FBG (a), and MWCNT-Fibrin (b). MWCNT-COOH (c). and FBG (d). Transmission-mode FT-IR spectroscopy was used to obtain
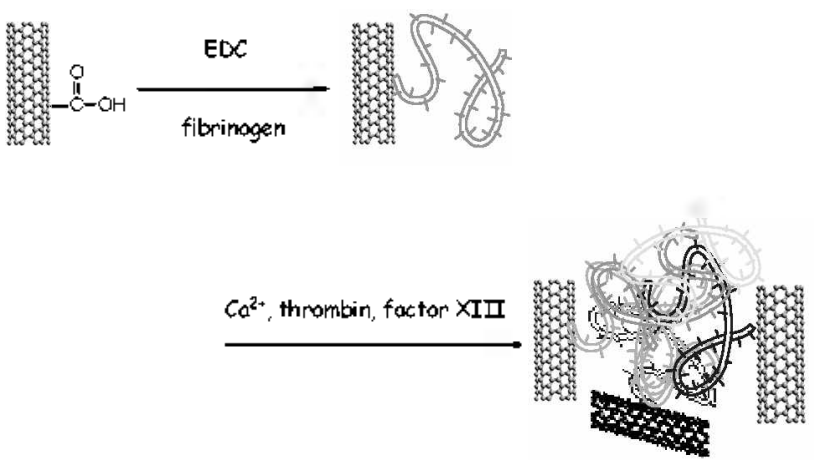

Scheme 1. Coupling of fibrinogen (FBG) with MWCNT-COOH and polymerization of MWCNT-FBG
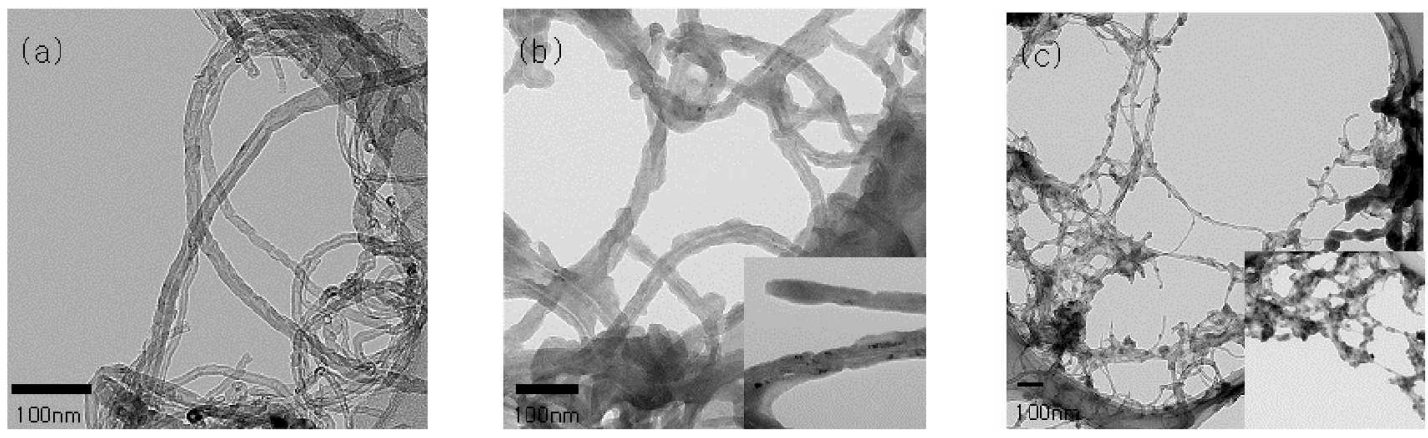

Figure 1. Transmission electron microscope (TEM) images of MWCNT-COOH(a), MWCNT- fibrinogen(b), MWCNT-Fibrin(c ). 

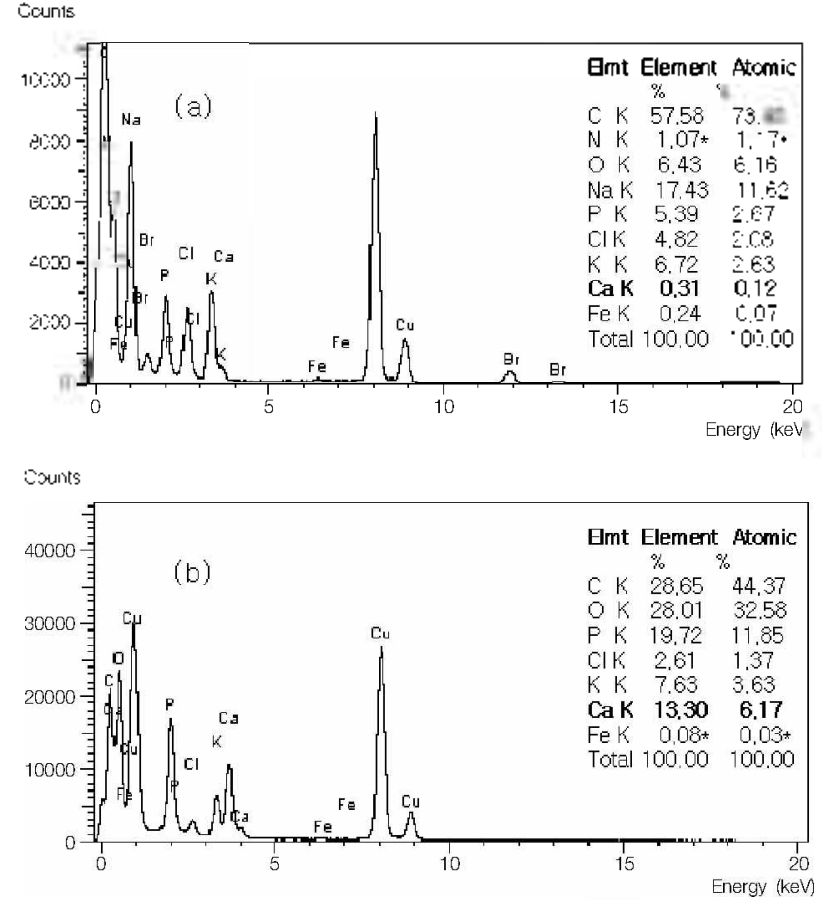

Figure 2. TEM-EDX analysis of MWCNT-tibrinogen (a) and MWCNT-Fibrin (b)

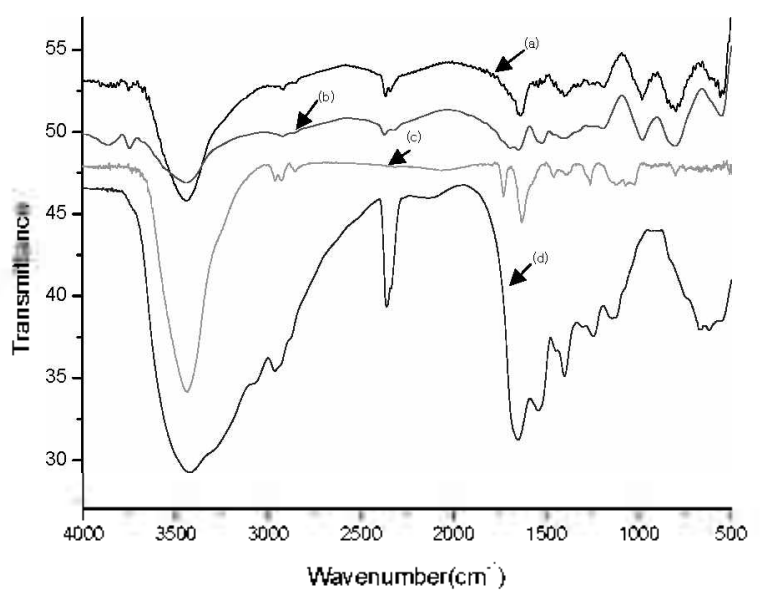

Figure 3. IR spectra of, MWCNT-fibrinogen (a), MWCNT- Fibrin (b), MWCNT-COOH (c), fibrinogen (d).

the secondary stnicture of MWCNT-FBG and MWCNT-Fibrin. The relative amounts of MWCNT-FBG and $\mathrm{KBr}$ were carefully controlled. The characteristic bands of FBG appeared at $1635 \mathrm{~cm}^{-1}$ (amide I ) and $1543 \mathrm{~cm}^{-1}$ (amide I ) in the spectra of MWCNT-FBG (3a). After the polymerization. we observed that the intensity of the peak of fibrinogen increased around $1689 \mathrm{~cm}^{.3}$ due to the increase of $\beta$-sheets ( $3 \mathrm{~b}$ ). The increase of $\beta$-sheets in fibrin after the polymerization with respect to FBG molecule were due to the increased formation of intramolecular and intermolecular $\beta$-sheets from the conformational changes of the staggered overlapping fibrillar array and their lateral association. ${ }^{31}$ The increase in the peak intensity. the signature bands of FBG. the TEM images of cross-linked fibrin. and increased $\beta$-sheet content. indicate that FBG retained a significant degree of biological function when immoblised to the carbon nanotubes. It raises the possibility that such material could be used in a coagulation reaction.

In addition enzymes involved in coagulation. such as thrombin FBG, and Factor XIII, could create barriers or sheet-like structures through the formation of fibrin networks. These networks in turn could be degraded in a safe and controlled manner by other enzymes. moreover such processes does not use strong acid and alkalis and might be considered as alternative to modem day microfabrication processes. In addition these types of materials could be incorporated in new types of integrated biosensors and bio-compatible single cell based detectors

\section{Conclusions}

In this study. the enzymatic polymerization of MWCNTFBG to MWCNT-Fibrin by thrombin and Factor XIII was completed. The process consisted of two simple steps. the conjugation of FBG with MWCNTs. followed by the in situ enzymatic polymerization of MWCNT-FBG to MWCNT-Fibrin In spite of chemical attachment of FBG to MWCNTs. FBG maintained its biological poly merization property. Since FBG could be dissolved easily in aqueous solution and fibrin can be degraded by plasmin. It might also be possible to generate new types of CNTs structures. These results highlight the potential applications of both FBG and MWCNTs.

Aclonowledgments. We greatly acknowledge the financial support provided by the Basic Research Program of the Korea Science \& Engineering Foundation (No. R01-2005-00010066-0). the Korea Science and Engineering Foundation (KOSEF) grant funded by the Korea government (MOST) (No. Rll-2007-050-02002-0) and the GRRC program of Gyeonggi province.

\section{Refeiences}

1. Harrison, B. S.; Atala, A. Biomaterials 2006, 28, 344

2. Choi, W. B.: Chung, D. S.: Kang. T. H.: Kim, H. Y.: Jin, Y. W.; Han, I. T.: Lee, Y. H., Jung, J. E.: Lee, N. S.: Park, G. S.: Kim, J. M. Appl Phus Let 1999, 75, 3129.

3. Dalton, A. B.; Collins, S.; Munot, E.: Razal, I. M.; Ebron, V. H.; Ferraris, J. P: Coleman, J. N.; Kim, B. G.: Banghman, R. H. Natue 2003, $423,703$.

4. Tavey, A.: Guo, I.: Wang. Q.; Lundstrom, M: Dai, H. Natme $2003,424,654$

5. Milne, W. I.: Teo, K. B. K.; Amaratunga, G. A. T.; Legagneus, P: Gangloff, L; Schnell, T. P; Semet, V: Binh, V. T.; Groening, O. J Hater Chent 2004, 14, 933.

6. Langer, R. Science 2001, 293, 58

7. Park, S.-T.; Taton, T. A.; Mirkint, C. A. Sicience 2002, 295, 1503.

8. Wang, J.; Musameh, M.; Lin, Y. I An Chem Soc 2003, 125, 2408

9. Baker, S. E.; Cai, W.; Lasseter, T. L.: Weidkamp, K. P: Hamers, R. J. Namo Lett 2002, 2, 1413.

10. Huang, W.: Taylor, S.; Fu, K.; Lin, Y,; Zhang, D.; Hanks, T. W. Rao, A. M.: Sun, Y.P. Nano Letr 2002, 2, 311

11. Viswanathan, G.: Chakrapani, N.: Yang. H.; Wei, B.; Chung, H.; Cho, K.; Ryu, C. Y.: Alayan, P. M. J Am Chem Soc 2003, 125 , 9258 .

12. Williams, K. A.: Veenhuizen, P. T. M.: de la Torre, B. G.: Erița, $\mathrm{R}$; Dekker, C. Noture 2002, $+20,761$. 
13. Fuss, C.: Palmaz, T. C.: Sprague, E. A. J Fasc Inter Radiol 2001, 12,677 .

14. Standeven, K. F.; Ariens, R. A. S.: Grant, P. J. Blood Rer 2005, 19,275 .

15. Wojtukiewicz, M. Z.; Sierko, E.; Rak, I. Semin Throntb Hentost $2004,30,5$.

16. Staton Carolyn, A.: Brown Nicola, T.; Lewis Claire, E. Expert Opin Biol Th 2003, 3, 1105

17. Eissa, S.; Kassin, S.; El-Almady, O. Curr Opin Obstet Gyn $2003,15,395$.

18. Wang, X.: Wang, E.; Kavanagh, I. T.; Freedman, R. S. J Transt Med 2005, 3, 25.

19. Dejana, E.: Zanetti, A.: Conforti, G. Haemostasis 1988, 18, 262.

20. Snith, E. B. Clin Haematol 1986, 15, 355.

21. Laurens, N.: Koolwiik, P.; De Maat, M. P. M. J Thromb Haenost $2006,+, 932$
22. Mosesson, M. W. J Thomb Haemost 2005, 3, 1894.

23. Seliktar, D. Am NY Acad Sci 2005, 1047, 386.

24. Amout, J.; Hoylaerts, M. F.; Lijnen, H. R. Handbook of Experimental Phamacolog 2006, 176, 1 .

25. Kannel, W. B. Lipids 2005, $70,1215$.

26. Lowe Gordon, D. O. Semin Iasc Med 2005, 5, 387.

27. Squizzato, A.; Ageno, W. Semin Iasc Med 2005, $5,379$.

28. Freyssinet, T. M; Lewis, B. A.; Holbrook, T. T.; Shore, T. D Biochem J 1978, 169, 403.

29. Chung, S. I.: Lewis, M. S.; Folk, I. E. J Biol Chem 1974, 249, 940 .

30. Bannerjee, D; Delaney, R; Morton, R. O.; Hampton, T. W. Ann MHAad Sci 1972, 202, 172.

31. Lin, S.-Y.; Wei, Y.-S.; Hsieh, T.-F.; Li, M.-J. Biopolymers 2004, 75,393 